\title{
Species richness and composition differ in response to landscape and biogeography
}

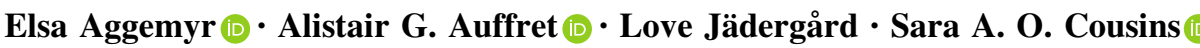

Received: 11 December 2017/ Accepted: 9 November 2018/Published online: 20 November 2018

(C) The Author(s) 2018

\begin{abstract}
Context Understanding how landscape patterns affect species diversity is of great importance in the fields of biogeography, landscape ecology and conservation planning, but despite the rapid advance in biodiversity analysis, investigations of spatial effects on biodiversity are still largely focused on species richness.

Objectives We wanted to know if and how species richness and species composition are differentially driven by the spatial measures dominating studies in
\end{abstract}

Electronic supplementary material The online version of this article (https://doi.org/10.1007/s10980-018-0742-9) contains supplementary material, which is available to authorized users.

E. Aggemyr · A. G. Auffret · L. Jädergård ·

S. A. O. Cousins $(\square)$

Biogeography and Geomatics, Department of Physical

Geography, Stockholm University, 10691 Stockholm,

Sweden

e-mail: sara.cousins@natgeo.su.se

E. Aggemyr

e-mail: elsa.aggemyr@natgeo.su.se

A. G. Auffret

e-mail: alistair.auffret@slu.se

L. Jädergård

e-mail: love.jadergard@schibsted.com

A. G. Auffret

Department of Ecology, Swedish University of

Agricultural Sciences, Box 7044, 75007 Uppsala, Sweden landscape ecology and biogeography. As both measures require the same limited presence/absence information, it is important to choose an appropriate diversity measure, as differing results could have important consequences for interpreting ecological processes.

Methods We recorded plant occurrences on 112 islands in the Baltic archipelago. Species richness and composition were calculated for each island, and the explanatory power of island area and habitat heterogeneity, distance to mainland and structural connectivity at three different landscape sizes were examined.

Results A total of 354 different plant species were recorded. The influence of landscape variables differed depending on which diversity measure was used. Island area and structural connectivity determined plant species richness, while species composition revealed a more complex pattern, being influenced by island area, habitat heterogeneity and structural connectivity.

Conclusions Although both measures require the same basic input data, species composition can reveal more about the ecological processes affecting plant communities in fragmented landscapes than species richness alone. Therefore, we recommend that species community composition should be used as an additional standard measure of diversity for biogeography, landscape ecology and conservation planning. 
Keywords Archipelago - Baltic Sea - Diversity measure $\cdot$ Island biogeography $\cdot$ Landscape variables . Plants $\cdot$ Species-area relationship $\cdot$ Species composition $\cdot$ Species richness $\cdot$ Structural connectivity

\section{Introduction}

The relationship between biodiversity, local environment and landscape patterns has long occupied biologists and ecologists (Forster 1778; Watson 1835; Darwin 1859; Wallace 1880; Arrhenius 1921; MacArthur and Wilson 1967; Hanski 1999). Today this relationship marks the cornerstone of island biogeography and landscape ecology, the former being of renewed interest, 50 years after its conception (Patiño et al. 2017; Whittaker et al. 2017). A wide range of studies within these disciplines have identified associations between biodiversity and habitat patch area (Arrhenius 1921; Lindgren and Cousins 2017), shape (Aggemyr and Cousins 2012), quality (De Sanctis et al. 2010) and isolation (MacArthur and Wilson 1967; Lindgren and Cousins 2017), as well as habitat amount (Fahrig 2013), configuration and connectivity within a landscape (Haddad et al. 2017), and historical properties of the focal habitat or landscape (Helm et al. 2005). These examples show that the physical environment can shape diversity in different ways, but in the majority of cases, the measure of diversity used is species richness, i.e. the raw number of species counted in a particular patch. As habitat patches with the same species richness might have completely different sets of species, it is time to look beyond species richness in landscape ecology and biogeography (Patiño et al. 2017).

Although measures exist that reflect community structure and the abundance or evenness of species (Gotelli and Chao 2013), species richness remains the focus of biogeographical and landscape ecological studies (Whittaker and Fernandez-Palacios 2007). Richness is the easiest diversity measure to collect in the field (Purvis and Hector 2000; Gotelli and Chao 2013) and useful for comparison across datasets (Fahrig 2017) or between historical and modern inventories (Aggemyr and Cousins 2012). Measuring diversity using species richness has a long history in the species-area relationship (SAR), which is one of the most fundamental and well-studied associations in ecology and biology, with overwhelming evidence that it exists (Arrhenius 1921; Kohn and Walsh 1994; Drakare et al. 2006).

In community ecology, it is common to use a multivariate approach, including species diversity measures that account for the presence and abundance of individual species, which may reflect different biotic and abiotic factors that are not captured by measures of species richness (Purvis and Hector 2000; Chiarucci et al. 2011; Jenkins and Ricklefs 2011). These analyses are often performed in tandem with analyses of species richness, finding that different land use and management variables explain species richness and composition, or do so to varying extents (e.g. Klimek et al. 2007; Schmucki et al. 2012). If we are to accurately interpret how species richness and composition relate to one another and how they respond to environmental changes such as land-use change, climate change and shifts in management, it is important that we first understand how these common measures of diversity relate to the classic underlying biogeographical and landscape-ecological drivers of population and community patterns. However, this has not yet been explicitly explored.

We present a comparison of two biodiversity measures on 112 islands in the Baltic Sea in relation to classic biogeographical and landscape ecological variables, and we ask whether species richness and species composition respond differently to local, landscape and biogeographical factors. Combining extensive plant surveys with measures of island area, distance to mainland, amount of bare bedrock, open and forest habitats, and structural connectivity, we ask how plant richness and species composition differ in relation to the spatial environment. Islands are excellent model systems for investigating landscape effects on biodiversity (Wardle 2002; Whittaker et al. 2017), and our results are therefore of relevance to the understanding and management of other fragmented habitats or ecosystems.

\section{Methods}

Study area

The study area is situated in the outer archipelago of Stockholm, Sweden, in the Baltic Sea, covering 
roughly $350 \mathrm{~km}^{2}, \quad$ (midpoint $59^{\circ} 15^{\prime} \mathrm{N}, \quad 18^{\circ} 50^{\prime} \mathrm{E}$ )

(Fig. 1). Approximately 10,000 years ago, the Late Weichselian deglaciation started, with the enormous weight of the thick ice-sheet suppressing the land. When the ice retreated, the land started to rebound, and today the isostatic rebound in the area has still significant landscape effects, with islands rising by approximately $4.6 \mathrm{~mm}$ per year (Auffret and Cousins 2018). The first islands in the study area started to appear c. 3000 years ago, and today the Stockholm archipelago consists of approximately 29,000 islands, ranging from smaller islets and skerries to larger islands with settlements. None of the islands included in this study have been connected to mainland by any

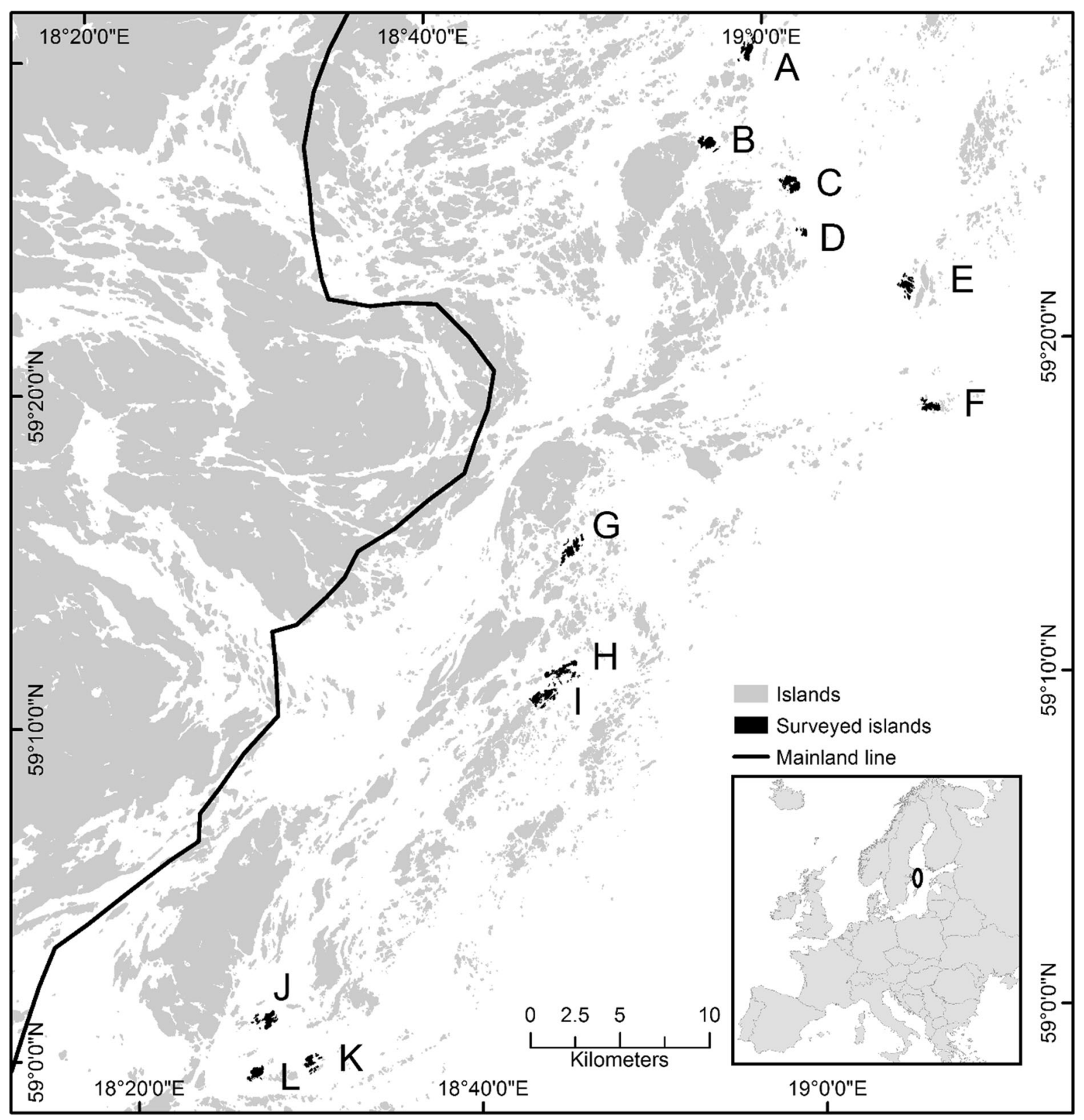

Fig. 1 The study area, situated in the outer archipelago of Stockholm, Sweden, in the Baltic Sea. Plant species richness and composition was surveyed on 112 islands (black) in 12 island groups (A-L). The surrounding landscape is represented by islands in grey. The black line represents the border to inner archipelago, here used for measuring distance to mainland 
land bridges (Fischer 2013), and the Baltic Sea is not influenced by tidal water. The mean precipitation is $600 \mathrm{~mm}$ per year, mean temperature in January is $-2{ }^{\circ} \mathrm{C}$ and in July $15{ }^{\circ} \mathrm{C}$ (Swedish Metrological and Hydrological Institute, SMHI 2016). The area belongs to the boreo-nemoral zone with a dominance of coniferous forests, although deciduous forests occur on many islands. However, on smaller skerries and islands in the outer archipelago the vegetation is sparse with few trees and no forest. When the islands rose above the sea most of the finer soil particles were washed away, leaving the islands with shallow soils, bare bedrock and pockets of deeper soils in sheltered positions. Soils are young and prone to drought thus the vegetation is often patchy. Most of the investigated islands are dominated by areas of low open vegetation with few trees and shrubs on thin soils and bare bedrock. Where the soils are deeper, conifers are found, mainly Pinus sylvestris and Juniperus communis, while broadleaf Alnus glutinosa is found on wetter soils. Beside junipers and alders, Rowans (Sorbus aucuparia) are among the first trees and shrubs to colonise the islands. We found a total number of 354 plant species on the 112 islands, with a mean of 58 ( $\pm 44 \mathrm{SD}$ ) species per island, (Table 1). The three most common species were Allium schoenoprasum (112 islands), Sedum telephium (106 islands), and Rumex crispus (103 islands). The most common species along the shoreline, reflecting the marine

Table 1 Summary data for all variables included in the study

\begin{tabular}{lllll}
\hline & Mean & SD & Min & Max \\
\hline Species richness & 58 & \pm 44 & 7 & 208 \\
Island area & 4.8 & \pm 10.8 & 0.002 & 54.4 \\
Island height & 6.5 & \pm 5.3 & 1.3 & 32.3 \\
Distance to mainland & 14.5 & \pm 5.0 & 6.8 & 24.0 \\
Habitat heterogeneity & 0.222 & \pm 0.240 & 0 & 1.04 \\
Connectivity 100 m & 4.7 & \pm 8.2 & 0 & 41.7 \\
Connectivity 1000 m & 16.1 & \pm 73.9 & 0.17 & 785.0 \\
Connectivity 4000 m & 81.8 & \pm 137.4 & 0.94 & 744.5 \\
\hline
\end{tabular}

Mean values (Mean), standard deviation (SD), minimum (Min), and maximum (Max) for species richness, island area (hectare), island height (metres), distance to mainland (kilometres), habitat heterogeneity, and structural connectivity (hectare) for the 112 islands in Stockholm archipelago, Baltic Sea influence, are Phalaris arundinacea, Lythrum salicaria and Schoenoplectus maritimus.

Species and landscape data

We surveyed plant species on 112 islands, 0.02-54.4 ha in size, distributed in 12 island groups in the outer Stockholm archipelago (Fig. 1). The 12 island groups were selected from islands in the outer archipelago, where their distinct grouping of islands facilitating fieldwork. Island groups ranged in size from three (groups B, D and F) to 19 (group I; Fig. 1) surveyed islands. All island groups contained additional skerries that were not included in the species inventories. Field surveys took place during two consecutive field seasons 2009-2010, from mid-June to mid-August. All islands were inventoried with equal sampling effort, approximately $45 \mathrm{~min}$ per hectare, walking back and forth across the whole of each island, observing the presence of plant species. Nomenclature followed Mossberg and Stenberg (2010). Plant species richness was calculated as number of species per island and plant species composition was represented in a binary matrix including species name and island and presence (1) or absence (0), without any information about abundance.

Candidate landscape variables consisted of island area, habitat heterogeneity, island height, distance to mainland, and structural connectivity (Table 1). Island area (hectare) was extracted from a digital terrain map from 2009 (1:50,000). Habitat heterogeneity on each island was calculated as the Shannon diversity of the three dominant land-cover types in the study area: open land, forest and bare rock, which were also extracted from the terrain map. Island height (m) was represented by the highest point of each island and extracted from a digital elevation model created from Lidar data from 2012, with a resolution of $1 \mathrm{~m}^{2}$ or less. The geography of our study region dictates that there is no clear line that marks the boundary between mainland and archipelago, due to much of the inner archipelago being based on a mixture of large islands and mainland peninsulas. We therefore classified a border based on a shift in landscape character from larger more sheltered islands with denser deciduous and coniferous forest, human-populated areas, roads and other infrastructure to smaller islands exposed to the open sea and with sparse vegetation or smaller 
coniferous forest (see Fig. 1). Distance to mainland $(\mathrm{km})$ was therefore measured as the Euclidean distance between island edge and this boundary. For structural connectivity we used a measure developed by Aggemyr and Cousins (2012) (Eq. 1), which is a non-species specific measure incorporating both habitat area and fragmentation. This means that a focal island surrounded by many small islands has a lower structural connectivity compared to an island that is surrounded by a few large islands encompassing the same area. This is to account for the fact that a larger island should contain more species that can disperse to the focal island. Connectivity measures such as this, that include information about size and distance of all potential source populations is especially desirable in highly fragmented habitats such as ours (Moilanen and Nieminen 2002). Three buffer distances were used to evaluate the effects of connectivity at local, landscape, and extended landscape scales on the diversity of each focal island. All islands within the buffer were included in the calculation, even those not surveyed for plant species.

$$
\begin{aligned}
C_{i} & =\sum_{\substack{j \neq i \\
j d_{i j}}} W_{A_{j}} W_{d_{j}} A_{j} \text { where } W_{A_{j}}=\frac{A_{j}}{\sum_{l \neq i} A_{l}} \text { and } W_{d_{j}} \\
& =k^{\frac{d^{r}}{r}}
\end{aligned}
$$

where $A_{j}$ is the area of island $j$ and $\sum_{l \neq i} A_{l}$ is the area of all surrounding islands within the buffer radius, $r$. For $W_{A_{j}}$ applies $0<W_{A_{j}} \leq 1$ and $\sum W_{A_{j}}=1$. The exponential function, $k^{\frac{d_{i j}}{r}}$, was assigned to $W_{d_{j}}$. The Euclidean distance, $d_{i j}$, is the distance between island $i$ and $j$, and $r$ is the buffer radius and $k$ is a constant scaling $W_{d_{j}}$ which is equal to $k$ when $d=r$. We set $\mathrm{k}$ to 0.01 . Independent of the value of $r$ we get $k \leq W_{d_{j}}<1$. The combination of $W_{A_{j}}$ and $W_{d_{j}}$ gives $0<W_{A_{j}} W_{d_{j}}$ $\leq 1$. $W_{d_{j}}$ gives less weight to islands further away from the focal island, but still within the buffer zone. The buffer distances $(r)$ used were $100 \mathrm{~m}$ (local), $1000 \mathrm{~m}$ (landscape) and $4000 \mathrm{~m}$ (extended landscape). All landscape variables were calculated using ArcGIS 10.2.2 (ESRI, Redlands, CA, USA).

\section{Statistical analysis}

Two models were built to analyse plant species richness and plant species composition, both including the full data set of 112 islands. To identify any collinearity between candidate environmental variables, Pearson product moment correlation coefficients were calculated for all variables: island area, island height (a proxy for island age), distance to mainland, habitat heterogeneity and structural connectivity. Strong correlations were identified between island area and island height (Pearson product moment correlation coefficient $=0.85)$, and between island area and habitat heterogeneity (Pearson product moment correlation coefficient $=0.78$ ). We therefore removed island height from further analysis, but in order to retain a measure of habitat heterogeneity, we calculated the residuals of a regression between island area and habitat heterogeneity to remove the common variance between these two variables, and thus to include only the variance specific to habitat heterogeneity. This variable is hereafter referred to as habitat heterogeneity (residualized). All remaining variables has coefficients of less than 0.7 (Dormann et al. 2013; Online Resource Table 1). In addition to calculating correlation coefficients, we also examined explanatory variables using variance inflation factors (VIFs). Values greater than 10 indicate multicollinearity (Chatterjee and Hadi 2012), but to be conservative, VIFs of 3 or above should be excluded (Zuur et al. 2010). Our remaining variables of islands area, distance to mainland, habitat heterogeneity (residualized) and structural connectivity at the local, landscape and extended landscape scales all had VIFs below 2 (Online Resource Table 1). Prior to analysis, variables representing an area (island area and structural connectivity) were $\log 10$ transformed. All explanatory variables were rescaled to fit a scale between 0 and 1 .

Since the data for species richness were overdispersed with a mean of 58 and variance of 1956, a generalized linear mixed model (GLMM) with a negative binomial distribution was built, with the above explanatory variables, while island group was included as a random factor to eliminate the effect of islands being geographically grouped (Fig. 1). ANOVA was used to test whether this random factor was significant, comparing the full model with and without it. To estimate the relative quality of the models we used Akaike information criterion (AIC) and stepwise backwards selection (Akaike 1974; Aho et al. 2014). When the best model was found, each variable within this model (island area, local 
connectivity, and extended landscape connectivity) was excluded one at a time and the significant contribution of each variable was tested using ANOVA at $\alpha=0.05$. We also created single-predictor models explaining species richness with each of these variables, plus island group as a random factor. Finally, plant species were also divided into four groups depending on life form: forbs, graminoids (families Poaceae, Juncaceae, and Cyperaceae), shrubs, and trees. Each group was analysed separately with GLMM to identify patterns for each species group separately, with island group as random factor. We used stepwise backward selection as method and the relative quality of the models was estimated using AIC (Online Resource Table 2). Statistical analysis was carried out using R 3.3.3 (R Core Team 2017), package usdm, function: vifstep (Naimi 2015), package lme4: function glmer.nb (Bates et al. 2014), package MASS: function glm.nb (Venables and Ripley 2002), and package vegan, function: diversity (Oksanen et al. 2018).

Plant species composition was analysed using partial canonical correspondence analysis (pCCA) to assess the effect of landscape variables on species composition. In the partial CCA, the variability in the species composition explained by island group was first subtracted and then a CCA was performed on the residual variability (Borcard et al. 1992; Lepš and Šmilauer 2003). All variables, i.e. island area, distance to mainland, habitat heterogeneity (residualized), structural connectivity at 100, 1000, and 4000 metres buffer radii were included. We also analysed the effect of each explanatory variable when no other was included (Lambda-1) and how much each explanatory variable contribute to the additional variance explained when included in the model (Lambda-A). Using automatic selection with Monte Carlo 499 permutations and $\alpha=0.05$, significant variables for species composition were analysed. As with species richness, we also analysed the data in groups according to life form. By analysing each group with only one significant variable at a time in a pCCA, the species scores indicate how the species are arranged along that variable (Online Resource Table 3). The pCCA was performed in CANOCO 4.5 (CANOCO for Windows Version 4.56, Biometris-Plant Research International, Wageningen, The Netherlands). Data have been deposited at the Figshare data repository: http://dx.doi.org/10.17045/sthlmuni.5607112 (Aggemyr et al. 2018).

\section{Results}

A total of 354 species were found on the 112 islands. Of these, 242 species were classified as forbs, 66 as graminoids, 30 as shrubs, and 16 as trees.

Plant species richness

Three variables were found to have significant effects in explaining species richness on the 112 islands after controlling for island group. By far the most important factor was island area, with more species being found on larger islands (estimate $=3.99$, standard error $=$ $0.15, \mathrm{p}<0.000$ ). Structural connectivity also had a positive effect on species richness, with higher connectivity at both at the local scale (buffer radius $100 \mathrm{~m}$; estimate $=0.24, \quad$ standard $\quad$ error $=0.11$, $\mathrm{p}=0.026$ ) and the extended landscape scale (buffer radius $4000 \mathrm{~m}$; estimate $=0.81$, standard error $=$ $0.32, p=0.012$ ) resulting in more species-rich island communities, with a stronger positive effect of connectivity in the extended landscape (Table 2). Although the above three variables were all significant in the final model and made significant contributions to the final model (ANOVA: island area $\mathrm{p}<0.000$, local-scale connectivity $\mathrm{p}=0.026$ and extended landscape-scale connectivity $\mathrm{p}=0.021$; Table 2 ), singlepredictor models (also including island group as a random factor) showed only island size to have a significant (positive) effect on species richness. Nonetheless, the final model containing all three variables fits the data better than the single-predictor island area model, as shown by the models' AIC (Table 2). The random factor island group was significant $(p=0.015)$. Variables not significant ( $p>0.05$ ) were distance to mainland, habitat heterogeneity (residualized), and landscape-scale structural connectivity. Patterns of species richness across species life forms were similar to those of the whole community, especially evident for forbs, the largest group (Online Resource Table 2). 
Table 2 Variables explaining plant species richness on 112 islands in a Baltic Sea archipelago. GLMM shows the fixed predictors present in the final generalized linear mixed-effects model that also contained island group as a random factor

\begin{tabular}{|c|c|c|c|c|c|c|c|}
\hline & \multirow[t]{2}{*}{ Estimate } & \multicolumn{3}{|l|}{ GLMM } & \multicolumn{2}{|l|}{ ANOVA } & \multirow[t]{2}{*}{ AIC } \\
\hline & & Standard error & Residual deviance & $\mathrm{p}$ Value & Chi square & $\mathrm{p}$ Value & \\
\hline \multicolumn{8}{|l|}{ Full model } \\
\hline Island area & 3.99 & 0.29 & & $<0.001$ & 216.2 & $<0.001$ & 1105.3 \\
\hline Conn 100 & 0.24 & 0.11 & & 0.03 & 4.9 & 0.03 & 894.1 \\
\hline Conn 4000 & 0.81 & 0.32 & & 0.01 & 5.3 & 0.02 & 894.5 \\
\hline \multicolumn{8}{|c|}{ Single variable } \\
\hline Island area & 3.98 & 0.16 & 889.4 & $<0.001$ & & & 897.4 \\
\hline Conn 100 & -0.03 & 0.29 & 1097.8 & 0.93 & & & 1105.8 \\
\hline Conn 4000 & 1.12 & 0.71 & 1095.3 & 0.12 & & & 1103.3 \\
\hline
\end{tabular}

ANOVA and AIC show the effect of removing each predictor from the full model containing all predictors. AIC of the full model was 891.1, residual deviance for the full model was 879.1, and residual deviance for the null model was 1097.8 with island group as random factor. A GLMM with island group as random factor was also performed for each single variable. Random factor was significant $(\mathrm{p}=0.015)$

Plant species composition

Species composition on the 112 islands revealed a more complex pattern, with island area and structural connectivity at a landscape scale the most important variables for species composition, controlling for the effect of island group. Habitat heterogeneity (residualized) followed by extended landscape and local connectivity, which were also significant predictors $(\alpha<0.05)$ of plant community composition on the islands. Island area had the highest effect on species composition, both when no other variable was included (Lambda-1) and in the full model (LambdaA). Since we used residualized habitat heterogeneity, the Lambda- 1 of 0.07 was the variance explained when the correlation effect between island area and habitat heterogeneity was removed. Distance to mainland had no effect on species composition $(p>0.05)$, however tree species were negatively influences by distance to mainland (Online Resource Table 3). The sum of all canonical eigenvalues was 0.419 and total inertia was 3.448 , which means that $12 \%$ of the variation in species composition could be explained by the environmental variables used in this analysis after the effect of island group was removed. Axis 1 explained $63.8 \%$ (eigenvalue 0.267 ) of the total explainable variance (the species-environment relation) of the data, and the cumulative percentage explained for axis one and two was $74.5 \%$ (eigenvalue for Axis 2 was 0.045). As with species richness, species composition showed generally the same trends when comparing species groups separately, although there was some variation in the effect of local-scale connectivity (Online Resource Table 3).

\section{Discussion}

We have demonstrated that plant species richness and composition differ significantly in their responses to local, landscape and biogeographical variables, with species composition showing the potential to offer additional insights to ecological processes when combined with the commonly-used measure of species richness. Island size was the dominant driver of both species richness and composition, following the species-area relationship and patch area's well-known effects on species richness (Arrhenius 1921; Drakare et al. 2006), turnover (Auffret et al. 2017a) and composition (Negoita et al. 2016). However, ecological processes are driven by factors relating to different elements of the landscape and at different scales, all of which can affect species occurrences in a focal patch (Plue and Cousins 2018). Indeed, we showed that species richness and composition responded to habitat heterogeneity and landscape connectivity at different spatial scales (Tables 2 and 3), while further patterns emerged when focussing on specific life forms (Online 
Table 3 Variables explaining $(\alpha=0.05)$ plant species composition on 112 islands in the Baltic Sea archipelago

\begin{tabular}{llll}
\hline Variable & Lambda-1 & Lambda-A & $p$ Value \\
\hline Island area & 0.26 & 0.26 & 0.002 \\
Connectivity $1000 \mathrm{~m}$ & 0.09 & 0.04 & 0.006 \\
Habitat heterogeneity (residualized) & 0.07 & 0.05 & 0.002 \\
Connectivity $4000 \mathrm{~m}$ & 0.04 & 0.04 & 0.026 \\
Connectivity $100 \mathrm{~m}$ & 0.03 & 0.03 & 0.028 \\
\hline
\end{tabular}

The variables are presented in inclusion order explaining plant species composition on the 112 islands included in the study. Lambda1 gives explained variance for the single variable model. Lambda-A gives the additional variance the variable explains, given the variables already included. Distance to mainland was not significant $\mathrm{p}>0.05$

Resource Table 3). Such additional landscape effects can for example give valuable guidance for conservation strategies, even when habitat area is known to be the strongest driver of biodiversity patterns (Sullivan et al. 2017).

\section{Species richness}

In accordance with studies from other island systems and fragmented terrestrial habitats, species richness on our 112 islands increased with increasing island area (MacArthur and Wilson 1967; Lindgren and Cousins 2017) (Table 2). We also found a positive effect on species richness with increasing structural connectivity at the local scale (buffer radius $100 \mathrm{~m}$ ) and at the extended landscape scale (buffer radius $4000 \mathrm{~m}$ ). At the local scale, nearby islands may function as source populations contributing to source-sink dynamics or by the rescue-effect, preventing species from going extinct (Brown and Kodric-Brown 1977; Piessens et al. 2004), or they might even act as extensions of the focal island itself and therefore allow the island to support a higher species richness. At the extended landscape scale, high values of connectivity indicate that there is simply more land surrounding the focal island that can host a larger species pool, which can then be reflected in the species richness of the focal island (Pärtel et al. 1996). Surprisingly, our results did not show a negative effect of distance to mainland on species richness, which alongside island size is a fundamental part of island biogeography theory (MacArthur and Wilson 1967). This could be explained by the islands' geographical position relatively far out into the archipelago relative to the common dispersal distances of most plant species
(Bullock et al. 2017). In previous work, we have shown that distance to mainland is an important predictor of plant species richness and immigration (Aggemyr and Cousins 2012; Auffret et al. 2017a), but these studies were carried out in a less isolated part of the Stockholm archipelago, closer to the mainland. In the current case, it could be that the connectivity at the wider landscape has replaced distance to mainland as a factor explaining species richness, being more appropriate to the dispersal ability of the taxonomic group studied here. Furthermore, the configuration of the surrounding landscape might have a positive effect with islands acting as stepping stones, an effect not captured by Euclidean measures such as distance to mainland. Other studies have also stressed the importance of the landscape configuration and its influence on plant species richness (Hernandez-Stefanoni 2005), with more fragmented landscapes often having lower species richness (Collinge 1996; Turner 1996; Laurance 2008; Cousins 2009).

\section{Species composition}

In contrast to species richness, plant species composition on an island was determined by habitat heterogeneity and structural connectivity at multiple scales alongside island area (Table 3). Not surprisingly, islands with more habitat types and a more heterogeneous distribution of these habitats were found to support different sets of plant species than islands with more homogeneous land cover. Elsewhere in the literature, habitat heterogeneity has been shown to be reflected in island height (Panitsa et al. 2008; Kougioumoutzis and Tiniakou 2015) We found that heterogeneity was highly correlated with both island 
height and island size (Online Resource Table 1), meaning that either could be used as a proxy in areas where land-use maps are unavailable. In our study system, island height is strongly related to island age as a result of isostatic land uplift, and hence soil development and successional stage. This itself can also be related to biodiversity in coastal habitats (Auffret and Cousins 2018). Habitat heterogeneity has also been found to be strongly linked to plant species richness (Stein et al. 2014), but habitat heterogeneity was only significant in determining species composition in our case. This could be because in our system, the strong effect of island area on species richness overrides all variables that occur within the island itself and that these only affect species composition to a significant extent. This illustrates that in other isolated and/or strongly fragmented systems, the use of species composition can be used to identify how additional patch-level variables drive variation in plant communities.

In addition to how island characteristics differed in determining species richness and composition, the scale at which structural connectivity determined community patterns also varied. For species composition, structural connectivity at the landscape scale (buffer $1000 \mathrm{~m}$ ) rather than at the local or extended landscape scale was the most important (Fig. 2). This might be because at this intermediate scale the landscape is more heterogeneous compared to the local scale but the dispersal distances required to reach the focal island are shorter compared to the largest

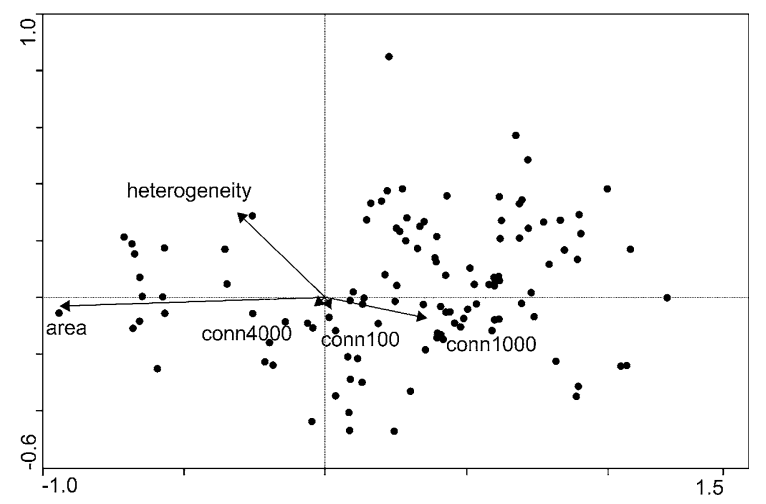

Fig. 2 A pCCA (the effect of island group partialled out) biplot for plant species composition on all 112 islands (dots) and significant explanatory variables (arrows); island area (area), habitat heterogeneity residualized (heterogeneity), and structural connectivity (conn), each number represent a buffer radius $(100,1000$, and $4000 \mathrm{~m})$ scale. Although seed dispersal usually occurs at local scales, distances of hundreds of metres to kilometres are not uncommon (Bullock et al. 2017), and can be important for colonizing new areas (Cain et al. 2000). Therefore, whereas connectivity at the local scale and extended landscape scale can explain species richness through the maintenance of individual populations and through a larger available species pool, respectively, having a number of different islands within plausible dispersal distances at the landscape scale can influence the identity of plant species present on the focal island.

Differences in species composition across islands with different local and landscape characteristics are almost certainly driven to some extent by species' functional traits. Species with different traits will be more or less abundant in the three main habitats identified on our study islands, with for example more drought-tolerant plants being more adapted to rocky areas and taller species with larger leaves are more likely to occupy forested habitats (Kimberley et al. 2014; Copeland et al. 2016). Seed dispersal, which is also strongly related to plant functional traits (Thomson et al. 2011; Tamme et al. 2014), will also determine which species disperse and how long it may take, while both structural connectivity and the plant species' ability to disperse and establish are important to understand how plant populations are connected in space (Negoita et al. 2016; Auffret et al. 2017b). Indeed, we have previously shown that plant functional traits and biogeographical and landscape variables interact to drive community turnover in the Stockholm archipelago, with for example good dispersal ability combining with proximity to mainland to increase immigration, and seed banking more likely to promote species persistence on larger islands (Auffret et al. 2017a). Interactions between functional traits and landscape parameters have been found elsewhere (Lindborg et al. 2012), and give valuable context to differences in plant species composition across environmental gradients.

\section{Outlook}

Although species richness can be an informative measure of diversity, plant communities are dynamic systems under constant change due to local extinction and immigration. As discussed above, community assembly and turnover are determined by the interactions between spatial structure and plant functional 
traits (Negoita et al. 2016; Auffret et al. 2017a), resulting in divergent species compositions while species richness remains tied to island size (Aggemyr and Cousins 2012). Our analyses show that using species richness alone can fail to capture both how within-patch environmental variation and key ecological processes such as immigration and extinction driving changes in community composition in time and space (Kadmon and Pulliam 1993; Wilsey et al. 2005; Morris et al. 2014). Therefore, it is clearly valuable to include species composition as a response variable in landscape ecological and biogeographical analyses.

In a world with continuing habitat destruction and fragmentation (Foley et al. 2005; Kuemmerle et al. 2016; Watson et al. 2016) it is essential for both researchers and practitioners to understand patterns of biodiversity in an area and how it is influenced by local and landscape conditions. Measurements of biodiversity therefore need to be efficient regarding the use of limited resources to investigate large areas but also to be comparable over time and between regions. While techniques to analyse biodiversity data are advancing rapidly (La Salle et al. 2016), investigations of spatial effects on biodiversity are still largely focused on species richness (Haddad et al. 2017; Whittaker et al. 2017). By using a comprehensive data set of plant species occurrences from 112 islands, we show that the inclusion of a measure of species composition can give a greater insight into the ecological processes occurring in a fragmented landscape than the number of species present. As only presence/absence data are required, we recommend that species community composition should be used as a standard and informative measure of diversity for biogeography, landscape ecology and conservation planning.

Acknowledgements The research was financed by the Swedish Research Council for Environment, Agricultural Sciences and Spatial planning (FORMAS), Ahlmanns Scholarship found, Lagrelius Scholarship found, Albert and Maria Bergströms foundation, and the strategic research program EkoKlim (now Bolin Center for Climate research) at Stockholm University. We are grateful to our field assistants E. Waldén, M. Ahlström, C. Essenberg, and to our "boat mechanic" A. Clarhäll. Many thanks also to Dr A. Kimberley, two anonymous referees and the subject editor for many constructive comments on earlier drafts of the manuscript.

Open Access This article is distributed under the terms of the Creative Commons Attribution 4.0 International License (http:// creativecommons.org/licenses/by/4.0/), which permits unrestricted use, distribution, and reproduction in any medium, provided you give appropriate credit to the original author(s) and the source, provide a link to the Creative Commons license, and indicate if changes were made.

\section{References}

Aggemyr E, Cousins SAO (2012) Landscape structure and land use history influence changes in island plant composition after 100 years. J Biogeogr 39:1645-1656

Aggemyr E, Jädergård L, Auffret AG, Cousins SAO (2018) Data from: species richness and composition differ in response to landscape and biogeography. Figshare Data Repos. https://doi.org/10.17045/sthlmuni.5607112

Aho K, Derryberry D, Peterson T (2014) Model selection for ecologists: the worldviews of AIC and BIC. Ecology 95:631-636

Akaike H (1974) A new look at the statistical model identification. IEEE Trans Autom Control AC 19:716-723

Arrhenius O (1921) Species and area. J Ecol 9:95-99

Auffret AG, Aggemyr E, Plue J, Cousins SAO (2017a) Spatial scale and specialization affect how biogeography and functional traits predict long-term patterns of community turnover. Funct Ecol 31:436-443

Auffret AG, Cousins SAO (2018) Land uplift creates important meadow habitat and a potential original niche for grassland species. Proc R Soc B 285:20172349

Auffret AG, Rico Y, Bullock JM, Hooftman DAP, Pakeman RJ, Soons MB, Suárez-Esteban A, Traveset Am Wagner HH, Cousins SAO (2017b) Plant functional connectivity-integrating landscape structure and effective dispersal. J Ecol 105:1648-1656

Bates D, Maechler M, Bolker B, Walker S (2014) Fitting linear mixed-effects models using lme4. J Stat Softw. https://doi. org/10.18637/jss.v067.i01

Borcard D, Legendre P, Drapeau P (1992) Partialling out the spatial component of ecological variation. Ecology 73:1045-1055

Brown JH, Kodric-Brown A (1977) Turnover rates in insular biogeography: effect of immigration on extinction. Ecology 58:445-449

Bullock JM, Mallada González L, Tamme R, Götzenberger L, White SM, Pärtel M, Hooftman DAP (2017) A synthesis of empirical plant dispersal kernels. J Ecol 105:6-19

Cain ML, Milligan BG, Strand AE (2000) Long-distance seed dispersal in plant populations. Am J Bot 87:1217-1227

Chatterjee S, Hadi AS (2012) Regression analysis by example, 5 th edn. Wiley, Hoboken

Chiarucci A, Bacaro G, Scheiner SM (2011) Old and new challenges in using species diversity for assessing biodiversity. Philos Trans 366:2426-2437

Collinge SK (1996) Ecological consequences of habitat fragmentation: implications for landscape architecture and planning. Landsc Urban Plan 36:59-77

Copeland SM, Harrison SP, Latimer AM, Damschen EI, Eskelinen AM, Fernandez-Going B, Spasojevic MJ, Anacker BL, Thorne JH (2016) Ecological effects of extreme 
drought on Californian herbaceous plant communities. Ecol Monogr 86:295-311

Cousins SAO (2009) Landscape history and soil properties affect grassland decline and plant species richness in rural landscapes. Biol Conserv 142:2752-2758

Darwin C (1859) On the origin of species by means of natural selection, or, the preservation of favoured races in the struggle for life. J. Murray, London

De Sanctis M, Alfò M, Attorre F, Francesconi F, Bruno F (2010) Effects of habitat configuration and quality on species richness and distribution in fragmented forest patches near Rome. J Veg Sci 21:55-65

Dormann CF, Elith J, Bacher S, Buchmann C, Carl G, Carré G, García Marquéz JR, Gruber B, Lafourcade B, Leitão PJ, Münkemüller T, McClean C, Osborne PE, Reineking B, Schröder B, Skidmore AK, Zurell D, Lautenbach S (2013) Collinearity: a review of methods to deal with it and a simulation study evaluating their performance. Ecography $36: 27-46$

Drakare S, Lennon JJ, Hillebrand H (2006) The imprint of the geographical, evolutionary and ecological context on species-area relationships. Ecol Lett 9:215-227

Fahrig L (2013) Rethinking patch size and isolation effects: the habitat amount hypothesis. J Biogeogr 40:1649-1663

Fahrig L (2017) Ecological responses to habitat fragmentation per Se. Annu Rev Ecol Evol Syst 48:1-23

Fischer SR (2013) Islands: from Atlantis to Zanzibar. Reaktion Books, London

Foley JA, DeFries R, Asner GP, Barford C, Bonan G, Carpenter SR, Chapin FS, Coe MT, Daily GC, Gibbs HK, Helkowski JH, Holloway T, Howard EA, Kucharik CJ, Monfreda C, Patz JA, Prentice IC, Ramankutty N, Snyder PK (2005) Global consequences of land use. Science 309:570-574

Forster JR (1778) Observations made during a voyage round the world: on physical geography, natural history, and ethnic philosophy, 1st edn. G. Robinson, in Pater-noster-Row, London

Gotelli NJ, Chao A (2013) Measuring and estimating species richness, species diversity, and biotic similarity from sampling data. Encyclopedia of biodiversity, 2nd edn. Academic Press, Waltham, pp 195-211

Haddad NM, Gonzalez A, Brudvig LA, Burt MA, Levey DJ, Damschen EI (2017) Experimental evidence does not support the habitat amount hypothesis. Ecography 40:48-55

Hanski I (1999) Metapopulation ecology, 1st edn. Oxford University Press, Oxford

Helm A, Hanski I, Pärtel M (2005) Slow response of plant species richness to habitat loss and fragmentation. Ecol Lett 9:72-77

Hernandez-Stefanoni J (2005) Relationships between landscape patterns and species richness of trees, shrubs and vines in a tropical forest. Plant Ecol 179:53-65

Jenkins DG, Ricklefs RE (2011) Introduction: biogeography and ecology: two views of one world. Philos Trans 366:2331-2335

Kadmon R, Pulliam HR (1993) Island biogeography: effect of geographical isolation on species composition. Ecology 74:978-981

Kimberley A, Blackburn GA, Whyatt JD, Smart SM (2014) Traits of plant communities in fragmented forests: the relative influence of habitat spatial configuration and local abiotic conditions. J Ecol 102:632-640

Klimek S, Richtergen, Kemmermann A, Hofmann M, Isselstein J (2007) Plant species richness and composition in managed grasslands: the relative importance of field management and environmental factors. Biol Conserv 134:559-570

Kohn DD, Walsh DM (1994) Plant species richness-the effect of island size and habitat diversity. J Ecol 82:367-377

Kougioumoutzis K, Tiniakou A (2015) Ecological factors driving plant species diversity in the South Aegean Volcanic Arc and other central Aegean islands. Plant Ecol Divers 8:173-186

Kuemmerle T, Levers C, Erb K, Estel S, Jepsen MR, Müller D, Plutzar C, Stürck J, Verkerk PJ, Verburg PH, Reenberg A (2016) Hotspots of land use change in Europe. Environ Res Lett 11:064020

La Salle J, Williams KJ, Moritz C (2016) Biodiversity analysis in the digital era. Phil Trans R Soc B 371:20150337

Laurance WF (2008) Theory meets reality: how habitat fragmentation research has transcended island biogeographic theory. Biol Conserv 141:1731-1744

Lepš J, Šmilauer P (2003) Multivariate analysis of ecological data using CANOCO, 1st edn. Cambridge University Press, Cambridge

Lindborg R, Helm A, Bommarco R, Heikkinen RK, Kühn I, Pykälä J, Pärtel M (2012) Effect of habitat area and isolation on plant trait distribution in European forests and grasslands. Ecography 35:356-363

Lindgren JP, Cousins SAO (2017) Island biogeography theory outweighs habitat amount hypothesis in predicting plant species richness in small grassland remnants. Landscape Ecol. https://doi.org/10.1007/s10980-017-0544-5

MacArthur RH, Wilson EO (1967) The theory of island biogeography. Princeton University Press, Princeton

Moilanen A, Nieminen M (2002) Simple connectivity measures in spatial ecology. Ecology 83:1131-1145

Morris EK, Caruso T, Buscot F, Fischer M, Hancock C, Maier TS, Meiners T, Müller C, Obermaier E, Prati D, Socher SA, Sonnemann I, Wäschke N, Wubet T, Wurst S, Rillig MC (2014) Choosing and using diversity indices: insights for ecological applications from the German Biodiversity Exploratories. Ecol Evol 4:3514-3524

Mossberg B, Stenberg L (2010) Den nya nordiska floran. Bonnier Fakta, Stockholm

Naimi B (2015) usdm: uncertainty analysis for species distribution models. $\mathrm{R}$ package version 1.1-15

Negoita L, Fridley JD, Lomolino MV, Mittelhauser G, Craine JM, Weiher E (2016) Isolation-driven functional assembly of plant communities on islands. Ecography 39:1066-1077

Oksanen J, Blanchet FG, Friendly M, Kindt R, Legendre P, McGlinn D, Minchin PR, O'Hara RB, Simpson GL, Solymos P, Stevens MHH, Szoecs E, Wagner H (2018) vegan: Community Ecology Package. $\mathrm{R}$ package version 2.4-6. https://CRAN.R-project.org/package=vegan

Panitsa M, Tzanoudakis D, Sfenthourakis S (2008) Turnover of plants on small islets of the eastern Aegean Sea within two decades. J Biogeogr 35:1049-1061

Pärtel M, Zobel M, Zobel K, van der Maarel E (1996) The species pool and its relation to species richness: evidence from estonian plant communities. Oikos 75:111-117 
Patiño J, Whittaker RJ, Borges PAV, Fernández-Palacios JM, Ah-Peng C, Araújo MB, Ávila SP, Cardoso P, Cornuault J, de Boer EJ, de Nascimento L, Gil A, González-Castro A, Gruner DS, Heleno R, Hortal J, Illera JC, Kaiser-Bunbury CN, Matthews TJ, Papadopoulou A, Pettorelli N, Price JP, Steinbauer MJ, Santos AMC, Triantis KA, Valente L, Vargas P, Weigelt P, Emerson BC (2017) A roadmap for island biology: 50 fundamental questions after 50 years of the theory of island biogeography. J Biogeogr 44:963-983

Piessens K, Honnay O, Nackaerts K, Hermy M (2004) Plant species richness and composition of heathland relics in north-western Belgium: evidence for a rescue-effect? J Biogeogr 31:1683-1692

Plue J, Cousins SAO (2018) Seed dispersal in both space and time is necessary for plant diversity maintenance in fragmented landscapes. Oikos 127:780-791

Purvis A, Hector A (2000) Getting the measure of biodiversity. Nature 405:212

R Core Team (2017) R: a language and environment for statistical computing. R Foundation for Statistical Computing, Vienna

Schmucki R, Reimark J, Lindborg R, Cousins SAO (2012) Landscape context and management regime structure plant diversity in grassland communities. J Ecol 100:1164-1173

Stein A, Gerstner K, Kreft H (2014) Environmental heterogeneity as a universal driver of species richness across taxa, biomes and spatial scales. Ecol Lett 17:866-880

Sullivan MJP, Pearce-Higgins JW, Newson SE, Scholefield P, Brereton T, Oliver TH (2017) A national-scale model of linear features improves predictions of farmland biodiversity. J Appl Ecol 54:1776-1784

Tamme R, Götzenberger L, Zobel M, Bullock JM, Hooftman DAP, Kaasik A, Pärtel M (2014) Predicting species' maximum dispersal distances from simple plant traits. Ecology 95:505-513
Thomson FJ, Moles AT, Auld TD, Kingsford RT (2011) Seed dispersal distance is more strongly correlated with plant height than with seed mass. J Ecol 99:1299-1307

Turner IM (1996) Species loss in fragments of tropical rain forest: a review of the evidence. J Appl Ecol 33:200-209

Venables WN, Ripley BD (2002) Modern applied statistics with S. Fourth Edition, New York

Wallace AR (1880) Island life: or, the phenomena and causes of insular faunas and floras, including a revision and attempted solution of the problem of geological climates. Macmillan \& Co., London

Wardle DA (2002) Islands as model systems for understanding how species affect ecosystem properties. J Biogeogr 29:583

Watson HC (1835) Remarks on the geographical distribution of British plants: chiefly in connection with latitude, elevation, and climate. Longman, Rees, Orme, Brown, Green, and Longman, Paternoster-Row

Watson JEM, Jones KR, Fuller RA, Marco MD, Segan DB, Butchart SHM, Allan JR, McDonald-Madden E, Venter O (2016) Persistent disparities between recent rates of habitat conversion and protection and implications for future global conservation targets. Conserv Lett 9:413-421

Whittaker RJ, Fernandez-Palacios JM (2007) Island biogeography: ecology, evolution, and conservation. OUP Oxford, Oxford

Whittaker RJ, Fernández-Palacios JM, Matthews TJ, Borregaard MK, Triantis KA (2017) Island biogeography: taking the long view of nature's laboratories. Science 357:eaam8326

Wilsey BJ, Chalcraft DR, Bowles CM, Willig MR (2005) Relationships among indices suggest that richness is an incomplete surrogate for grassland biodiversity. Ecology $86: 1178-1184$

Zuur AF, Ieno EN, Elphick CS (2010) A protocol for data exploration to avoid common statistical problems. Methods Ecol Evol 1:3-14 